\title{
Componentes de produção de mamona em função de níveis de adubação nitrogenada e desfolha ${ }^{1}$
}

\author{
Yield-components of the castor-bean as a function of nitrogen fertilization and \\ defoliation levels
}

\author{
Manoel Alexandre Diniz Neto ${ }^{2 *}$, Ivandro de França da Silva ${ }^{3}$, Belísia Lúcia Moreira Toscano Diniz ${ }^{4}$, Adelaido de \\ Araújo Pereira ${ }^{5}$ e Alécio Rodrigues Pereira ${ }^{5}$
}

\begin{abstract}
RESUMO - Objetivou-se com esse trabalho, avaliar os componentes de crescimento e produção da mamoneira submetida à adubação nitrogenada combinada com desfolha artificial da planta. O experimento foi conduzido na Estação Experimental da Empresa Estadual Agropecuária da Paraíba (Emepa-PB) localizada no município de Alagoinha-PB, entre os meses de abril e outubro de 2009. Foram utilizados cinco níveis de N-fertilizante (00-30-60-90-120 kg ha-1) combinados com quatro níveis de desfolha artificial (00-20-40-60\%), distribuídos no delineamento de blocos ao acaso, com quatro repetições em arranjo fatorial 5 x 4. Foram avaliadas altura de planta, diâmetro caulinar, número de nós, massa de 100 grãos e produtividade de grãos. As variáveis de crescimento aumentam com os níveis de $\mathrm{N}$-fertilizante nos níveis de desfolha de até $20 \%$. A partir desse nível, há tendência de maior crescimento vegetativo com a aplicação de menores doses de nitrogênio. A massa de 100 grãos e a produtividade de grãos aumentam com doses menores que $120 \mathrm{~kg} \mathrm{ha}^{-1}$ de $\mathrm{N}$-fertilizante em níveis de desfolha de até $40 \%$, mostrando que há correlação positiva entre essas variáveis de produção da mamoneira. A desfolha artificial quando combinada com adubação nitrogenada provoca alterações nos componentes de crescimento e de produção da mamoneira, sendo importante avaliar até que ponto é economicamente viável a aplicação do $\mathrm{N}$-fertilizante e a possibilidade do uso de fontes alternativas desse nutriente.
\end{abstract}

Palavras-chaves: Ricinus communis L. Folha. N-Fertilizante.

\begin{abstract}
The objective of this study was to evaluate the growth and yield components of castor beans subjected to nitrogen fertilization combined with the artificial defoliation of the plant. The experiment was carried out at the Experimental Station of the Paraiba State Agricultural Company (Emepa-PB) located in the town of Alagoinha-PB, between the months of April and October, 2009. Five levels of $\mathrm{N}$-fertilizer (00,30,60,90, $\left.120 \mathrm{~kg} \mathrm{ha}^{-1}\right)$ were used, combined with four levels of artificial defoliation $(00,20,40,60 \%)$, distributed in a randomized-block design, in a $4 \times 5$ factorial arrangement, with four replications. Plant height, stem diameter, number of nodes, 100-grain mass and grain yield were evaluated. Growth variables increase with the levels of N-fertilizer at defoliation levels of up to $20 \%$. From this level on, there is a tendency for greater vegetative growth with the application of lower doses of nitrogen. Both the 100-grain mass and grain yield increase at $\mathrm{N}$-fertilizer doses of less than $120 \mathrm{~kg} \mathrm{ha}^{-1}$ and defoliation levels of up to $40 \%$, showing that there is a positive correlation between these yield variables of the castor bean. Artificial defoliation, when combined with nitrogen fertilisation, causes changes in the growth and yield components of the castor bean, it being important to assess to what extent the application of $\mathrm{N}$-fertilizer is economically viable, and the possibility of using alternative sources of this nutrient.
\end{abstract}

Key words: Ricinus communis L. Leaf. N-fertilizer.

\footnotetext{
* Autor para correspondência

${ }^{1}$ Recebido para publicação em 27/12/2010; aprovado em 10/02/2012

Pesquisa financiada pela FAPESQ - Fundação de Apoio à Pesquisa do Estado da Paraíba e CNPq

${ }^{2}$ Pós-Doutorando do Centro de Ciências Agrárias da Universidade Federal da Paraíba, Areia-PB, Brasil, diniznetto@gmail.com

${ }^{3}$ Centro de Ciências Agrárias da Universidade Federal da Paraíba, Areia-PB, Brasil, ivandro@cca.ufpb.br

${ }^{4}$ Centro de Ciências Humanas, Sociais e Agrárias da Universidade Federal da Paraíba, Bananeiras-PB, Brasil, belisialucia@cchsa.ufpb.br

${ }^{5}$ Estagiários do Centro de Ciências Agrárias da Universidade Federal da Paraíba, Areia-PB, Brasil, adelaido-p@hotmail.com, aleciorodrigues@ hotmail.com
} 


\section{INTRODUÇÃO}

Pertencente à família Euphorbiaceae, a mamoneira (Ricinus communis L.) é uma espécie de oleaginosa de significativo valor socioeconômico com produtos e subprodutos utilizados na indústria ricinoquímica e na agricultura, possibilitando seu uso como biocombustível devido ao óleo que é extraído de suas sementes, embora com produtividade de grãos ainda baixa para seu potencial (ALMEIDA, et al., 2007; RIBEIRO, et al., 2009).

Mesmo com muitos trabalhos de pesquisa (RIBEIRO et al., 2010; SILVA et al., 2007; SOUZA et al., 2007; ZUCHI et al., 2010) conduzidos com o objetivo de avaliar e melhorar seu potencial produtivo, a mamoneira apresenta rendimentos médios ainda baixos nas áreas de produção no país, o que pode ser devido ao baixo nível tecnológico empregado, principalmente pela não fertilização dos solos explorados com esta cultura em pequenas propriedades, devido à falsa idéia de que essa espécie é pouco exigente em adubação (QUEIROGA; SANTOS, 2008; SOUZA et $a l ., 2007)$, fato que é comprovado por pesquisas através de marchas de absorção de nutrientes conforme relatado por Nakagawa e Neptune, (1971) concluindo que plantas de mamona são extremamente exigentes em nutrição e que para produção de uma tonelada de grãos, pode extrair até $40 \mathrm{~kg}$ de $\mathrm{N} ; 9 \mathrm{~kg}$ de $\mathrm{P}_{2} \mathrm{O}_{5}$ e $16 \mathrm{~kg}$ de $\mathrm{K}_{2} \mathrm{O}$ por hectare evidenciando que o nitrogênio é o principal elemento absorvido, embora em estudos realizados por Pacheco et al. (2008) o fósforo foi absorvido em maiores quantidades.

Entretanto, independente da situação, faz-se necessário que sejam equacionados os problemas de fertilidade do solo onde se deseja cultivar esta espécie para o estabelecimento mais rápido das plantas e o alcance de maiores produtividades mesmo em regiões que apresentem limitações climáticas (FERREIRA et al., 2006; GUIMARÃES et al., 2008).

Em regiões com condições climáticas adversas, como baixa precipitação, é aconselhável a semeadura de variedades adaptadas, pois nestas condições as plantas de mamona, no início do crescimento vegetativo, investem boa parte de sua energia na produção de fitomassa radicular em detrimento à fitomassa da parte aérea, permitindo a produção de um sistema radicular mais vigoroso e profundo, explorando e absorvendo nutrientes e água num maior volume de solo, em regiões onde a água é o fator climático limitante (GONÇALVES et al., 2005) o que por esse motivo, principalmente em regiões do Nordeste brasileiro, esta oleaginosa tem sido indicada como importante matéria-prima para uso no Programa Nacional de Biodiesel, devido à excelente adaptação às condições edafoclimáticas da região (SOUZA et al., 2007). Entretanto, trabalhos realizados por Zuchi et al. (2010) ficou constatado que plantas de mamona cultivadas em condições ambientais com longos períodos de estiagem, podem ter sua produção significativamente afetada pelo menor peso dos grãos produzidos.

Considerada uma planta rústica, pois em lugares de baixa precipitação pluvial consegue alcançar boa produção de fitomassa (BARROS JÚNIOR et al., 2008; COSCIONE; BERTON, 2009), sendo essa característica a que mais favoreceu sua disseminação pelo mundo (CARVALHO et al., 2010), poucos estudos têm sido realizados com o objetivo de agregar valor à sua exploração utilizando a biomassa aérea em especial as folhas, cujo índice de área foliar varia de 2 a 4 , com média de 3 , ensejando em um hectare uma média de $30.000 \mathrm{~m}^{2}$ de folhas (BELTRÃO et al., 2007) o que, em grande parte, poderiam ser utilizadas para a alimentação de ruminantes e formulação de biofertilizantes líquidos, alternativas que fortaleceriam a cadeia produtiva do agronegócio da mamona no Nordeste.

Caracterizada pela abscisão foliar gradativa à medida que avançam os estádios fenológicos, o cultivo da mamoneira pode representar um importante aporte de $\mathrm{C}$ e de nutrientes ao solo, pois durante a decomposição de suas folhas, parte dos nutrientes acumulados nas mesmas são mineralizados, podendo ser reutilizados pela própria planta (SCHMALZ et al., 2007).

Quando ainda naplanta, essas folhas podem ser úteis na alimentação animal, fato que vem sendo demonstrado por pesquisas caracterizando seus teores nutricionais, reforçando a idéia de que há possibilidade de utilização de suas folhas na nutrição de ruminantes, estando os teores nutricionais bem acima dos encontrados na maioria das forrageiras comumente utilizadas na nutrição desses animais (EVANGELISTA et al., 2006).

Com o objetivo de avaliar o comportamento produtivo da cultivar de mamona BRS Energia, foi lançado um experimento a campo utilizando cinco doses crescentes de nitrogênio combinados com quatro proporções de desfolhamento artificial, como forma de estudar a possibilidade de utilização da parte aérea dessa espécie durante seu ciclo de desenvolvimento.

\section{MATERIAL E MÉTODOS}

A pesquisa foi conduzida em 2009 entre os meses de abril e agosto e localizada na Estação Experimental da Empresa Estadual de Pesquisa Agropecuária da Paraíba (EMEPA-PB), município de Alagoinha-PB em solo classificado como LUVISSOLO CRÔMICO Pálico abrúptico (EMPRESA BRASILEIRA DE PESQUISA AGROPECUÁRIA, 2006), com clima do tipo As', caracterizando-se por apresentar uma estação chuvosa de 
outono-inverno, sendo quente e úmido pela classificação de Köppen (BRASIL, 1972), com precipitação média anual de $1.100 \mathrm{~mm}$.

A caracterização química e físico-química do solo na profundidade de $0-40 \mathrm{~cm}$ está apresentada na Tabela 1. Vale ressaltar que geralmente, não se mede o teor de nitrogênio no solo, mas apenas o teor de Matéria Orgânica (M.O.), sendo a recomendação feita indiretamente. Para o cultivo da mamoneira é indicado o seguinte procedimento: em solo com baixo teor de M.O. (< $10 \mathrm{~g} \mathrm{~kg}^{-1}$ ) recomenda-se doses de nitrogênio de até $60 \mathrm{~kg} \mathrm{ha}^{-1} \mathrm{e}$; em solo com teor alto de M.O. (> $30 \mathrm{~g} \mathrm{~kg}^{-1}$ ) a dose pode ser reduzida para até $15 \mathrm{~kg} \mathrm{ha}^{-1}$ (EMPRESA BRASILEIRA DE PESQUISA AGROPECUÁRIA ALGODÃO, 2007a).

Os tratamentos foram compostos pela aplicação de cinco níveis de $\mathrm{N}$-fertilizante (00-30-60-90-120 kg ha-1), mantendo-se constante a aplicação de fósforo e potássio em 164 e 26,3 kg ha-1, respectivamente, conforme indicado pela análise do solo. Utilizou-se como fonte de nutrientes a ureia, o superfosfato simples e o cloreto de potássio como fontes de nitrogênio, fósforo e potássio, respectivamente. A aplicação da adubação de fundação foi realizada apenas com o fósforo e o potássio e a adubação nitrogenada fracionada em três porções: $1 / 3$ aos 45 dias; $1 / 3$ aos 90 dias e $1 / 3$ aos 135 dias após a semeadura da mamoneira. Esse fracionamento foi feito levando-se em consideração a recuperação do crescimento vegetativo, visto que as plantas estavam passando pelo processo de desfolha artificial.

Os tratamentos que compreenderam a desfolha artificial foram em quatro proporções (00-20-40-60\%) da área foliar de todas as plantas da parcela. Para tanto, contou-se o número total de folhas por planta e retirouse a quantidade de folhas com o auxílio de um alicate de poda correspondendo a porcentagem referida em cada tratamento. Os desfolhamentos correspondentes aos tratamentos foram realizados por três vezes em 45; 90 e 135 dias após a emergência das plântulas.

As plantas da cv. BRS Energia têm porte baixo, em torno de 1,40 m, ciclo entre 120 e 150 dias, caule verde com cera, cachos cônicos com tamanho médio de $60 \mathrm{~cm}$, frutos indeiscentes, com peso médio de 100 grãos entre $0,40 \mathrm{~g}$ a $0,53 \mathrm{~g}$ nas cores marrom e bege com mosqueados, contendo $48 \%$ de óleo e produtividade média experimental de $1.500 \mathrm{~kg} \mathrm{ha}^{-1}$ em anos normais de chuva (EMPRESA BRASILEIRA DE PESQUISA AGROPECUÁRIA ALGODÃO, 2007b).

A mamona foi semeada manualmente no início do mês de abril utilizando espaçamento de 2,0 x 2,0 m com quatro fileiras por parcela que mediram $10 \times 6 \mathrm{~m}$ cada, escolhendo-se quatro plantas do centro da parcela como área útil. Os blocos constavam de vinte parcelas cada e mediam 120 x $10 \mathrm{~m}$, com área total de 120 x $40 \mathrm{~m}$, ou seja, $4.800 \mathrm{~m}^{2}$. Após a colheita dos cachos, realizada entre agosto e setembro de 2009, foram estudadas as variáveis altura de planta $(\mathrm{cm})$; diâmetro caulinar $(\mathrm{mm})$; número de nós (unid.); peso de 100 grãos (g) e produtividade de grãos $\left(\mathrm{kg} \mathrm{ha}^{-1}\right)$ que apresentaram interações significativas entre os fatores adubação nitrogenada e desfolhamento.

Os dados foram analisados utilizando-se $\mathrm{o}$ delineamento experimental de blocos casualizados com fatorial 5 x 4 (cinco níveis de $\mathrm{N}$-fertilizante e 4 níveis de desfolha) com quatro repetições e foram submetidos à análise de variância para verificar o efeito dos tratamentos em relação aos componentes de incremento vegetativo e produtivo da mamoneira e, de acordo com o nível de significância no teste $\mathrm{F}$ para os níveis de nitrogênio e desfolha, procedendo-se análise de regressão polinomial, de modo que os modelos polinomiais apresentados foram aqueles de melhor ajuste. Vale ressaltar que os tratamentos com doses de $\mathrm{N}$-fertilizante e níveis de desfolha eram quantitativos, de modo que justifica a utilização da análise de regressão por polinômios ortogonais (FERREIRA, 2000).

Adotou-se, para a escolha do modelo, a magnitude dos coeficientes de regressão significativos aos níveis de $1 \%$ e $5 \%$ de probabilidade de erro pelo teste " $t$ " utilizandose o software estatísticoASSISTAT versão 7.5 beta (SILVA; AZEVEDO, 2002). Para estimar a dose máxima de Nfertilizante no modelo polinomial quadrático, utilizouse a derivada da equação de regressão encontrada pelo método estatístico recomendado para dados quantitativos (FERREIRA, 2000).

Tabela 1 - Atributos químicos e físico-químicos do solo da área experimental, coletado na propriedade de 0-40 cm. Alagoinha, 2009

\begin{tabular}{|c|c|c|c|c|c|c|c|c|c|c|}
\hline \multicolumn{11}{|c|}{ Determinações } \\
\hline $\mathrm{pH}$ & $\mathrm{P}$ & $\mathrm{K}$ & $\mathrm{Na}$ & $\mathrm{Ca}$ & $\mathrm{Mg}$ & $\mathrm{H}+\mathrm{Al}$ & $\mathrm{Al}$ & CTC & $\mathrm{V}$ & M.O. \\
\hline $\mathrm{H}_{2} \mathrm{O}(1: 2,5)$ & $\mathrm{mg} \mathrm{dm}^{-3}$ & ------ & ------ & $---\mathrm{cmc}$ & $n^{-3}----$ & -------- & ------- & - & $(\%)$ & $\mathrm{g} \mathrm{kg}^{-1}$ \\
\hline 5,85 & 5,62 & 171 & 0,40 & 3,55 & 1,70 & 5,25 & 0,05 & 11,03 & 55,12 & 18,68 \\
\hline
\end{tabular}

Fonte: Laboratório de Química e Fertilidade do Solo (CCA/UFPB) 


\section{RESULTADOS E DISCUSSÃO}

As maiores precipitações mensais foram registradas nos meses de abril (semeadura) a agosto, perfazendo mais de $96 \%$ do total de chuvas precipitadas no período de condução do experimento. Nesse período foram registrados problemas quanto à germinação de sementes em algumas parcelas devido ao excesso de umidade no solo. Entretanto, como estava no início do experimento, foi feito o replantio dessas parcelas, de modo que garantiu o crescimento uniforme das plantas estudadas. Vale ressaltar que esse ano agrícola foi atípico em relação à pluviosidade na região, onde mais de $1.400 \mathrm{~mm}$ de chuvas durante o ano foram registrados pela Estação Meteorológica da EMEPA-PB, conforme pode-se observar na Tabela 2.

Através da análise de variância, foi constatado efeito significativo dos níveis de nitrogênio $(\mathrm{N})$ ao nível de $1 \%$ para todas as variáveis analisadas, exceção feita apenas para o número de nós até o primeiro cacho (NNO), que foi de 5\% de probabilidade. Enquanto que para desfolha, a exceção do número de nós até o primeiro cacho (NNO) que não foi significativo, houve efeito a $5 \%$ de probabilidade para as demais variáveis estudadas. Para interação nitrogênio $\mathrm{x}$ desfolha, observou-se significância para todas as características avaliadas neste trabalho, conforme Tabela 3 .

$\mathrm{Na}$ Figura 1 pode-se observar que as plantas cresceram linearmente em altura sem $(0 \%)$ e com $20 \%$ de desfolha ao nível de $0,84 \mathrm{~cm}$ e $0,38 \mathrm{~cm}$, respectivamente, com o incremento unitário do fertilizante fornecido atingindo valores máximos de 1,94 e 1,61 m na altura das plantas. Com o desfolhamento nas proporções de 40 e $60 \%$ as plantas apresentaram um comportamento diferente em relação às porcentagens $0 \%$ e $20 \%$, ajustando-se ao modelo quadrático. Nesse caso, as plantas com $40 \%$ de desfolha cresceram à medida que houve incremento na aplicação de nitrogênio até a dose estimada de $62 \mathrm{~kg} \mathrm{ha}^{-1} \mathrm{de} \mathrm{N}$. Ainda na Figura 1, as plantas com $60 \%$ de desfolha a dose máxima estimada foi de $80,5 \mathrm{~kg} \mathrm{ha}^{-1}$ de $\mathrm{N}$. Nas duas proporções de desfolha (40 e 60\%) as plantas cresceram até a altura de 1,58 e $1,79 \mathrm{~m}$, respectivamente.

Tabela 2 - Precipitação pluvial durante a condução do experimento no ano agrícola de 2009. Alagoinha-PB, 2009

\begin{tabular}{|c|c|c|c|c|c|c|c|c|c|c|c|c|}
\hline \multirow{3}{*}{$\begin{array}{l}\text { Período } \\
\text { (dias) }\end{array}$} & \multicolumn{12}{|c|}{ Meses } \\
\hline & Jan & Fev & Mar & Abr* & Mai & Jun & Jul & Ago & Set & Out & Nov & Dez \\
\hline & \multicolumn{12}{|c|}{ 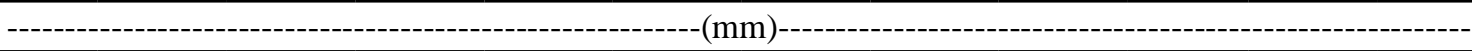 } \\
\hline $1-6$ & - & 20,3 & 53,5 & 31,2 & 9,5 & 26,4 & 82,2 & 26,5 & - & - & - & - \\
\hline $7-12$ & - & 2,0 & - & 102,6 & 31,6 & 7,4 & 87,5 & 70,0 & 7,4 & - & - & - \\
\hline $13-18$ & 47,3 & 28,7 & 10,7 & 41,1 & 18,5 & 0,8 & 14,6 & 8,1 & 17,7 & - & 7,5 & - \\
\hline $19-24$ & 0,8 & 56,3 & - & 36,1 & 51,0 & 74,2 & 79,9 & 11,5 & - & - & - & 6,2 \\
\hline $25-31$ & 37,2 & 1,7 & 43,2 & 86,5 & 65,9 & 30,2 & 3,8 & 79,1 & 1,3 & - & 3,0 & 1,8 \\
\hline Total & 85,3 & 109,0 & 107,4 & 297,5 & 176,5 & 165,8 & 268,0 & 195,2 & 26,4 & - & 10,5 & 8,0 \\
\hline
\end{tabular}

*Mês referente ao início da semeadura

Tabela 3 - Resumo da análise de variância para altura de plantas (ALP), diâmetro caulinar (DIC), número de nós até o primeiro cacho (NNO), massa de cem sementes (MCS) e produtividade (PRO) de mamona sob níveis de N-fertilizante e desfolha

\begin{tabular}{lcccccc}
\hline \multirow{2}{*}{ FV } & GL & \multicolumn{3}{c}{ Quadrado médio } \\
\cline { 3 - 6 } \multicolumn{1}{c}{} & & ALP & DIC & NNO & MCS & PRO \\
\hline Nitrogênio (N) & 4 & $0,70^{* *}$ & $190,73^{* *}$ & $5,86^{*}$ & $141,78^{* *}$ & $340.196,50^{* *}$ \\
Desfolha (D) & 3 & $0,17^{*}$ & $31,39^{*}$ & $0,43^{\text {ns }}$ & $10,09^{*}$ & $60.137,71^{*}$ \\
N x D & 12 & $0,11^{*}$ & $19,11^{* *}$ & $2,42^{*}$ & $17,01^{* *}$ & $29.815,58^{*}$ \\
Erro & 38 & 0,06 & 6,41 & 0,97 & 2,84 & $12.621,76$ \\
CV $(\%)$ & - & 16,5 & 10,15 & 6,97 & 5,51 & 15,26 \\
\hline
\end{tabular}

${ }^{* *},{ }^{*} \mathrm{e}^{\mathrm{ns}}-$ significativos a $1 \% ; 5 \%$ e não significativo, respectivamente pelo teste $\mathrm{F}$ 
Figura 1 - Curvas de resposta da mamoneira cv. BRS Energia sob diferentes doses de $\mathrm{N}$-fertilizante combinados com quatro porcentagens de desfolhamento sobre a altura de plantas. Alagoinha-PB, 2009

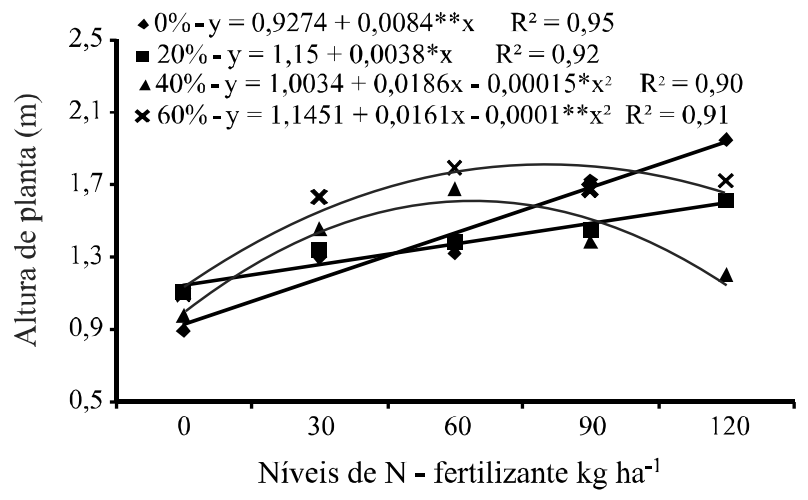

O crescimento da mamoneira está diretamente relacionado à nutrição durante os estádios fenológicos da cultura, pois com o aumento na disponibilidade de nutrientes, há maior crescimento lateral e, consequente aumento da competição por luz, o que leva à indução para um maior crescimento em altura, podendo prolongar o tempo para o início do florescimento (DINIZ NETO et al., 2009; SEVERINO et al., 2006). Embora a cv. BRS Energia apresente um porte baixo, média de 1,40 m (EMPRESA BRASILEIRA DE PESQUISA AGROPECUÁRIA ALGODÃO, 2007b), no tratamento controle (0\%) e na menor proporção de desfolha (20\%), as plantas apresentaram aumento crescente com o incremento da aplicação do nitrogênio no solo devido possivelmente, à presença de maior número de folhas, possibilitando sintetizar e assimilar maior quantidade de carboidratos produzidos pelo processo fotossintético (TAIZ; ZEIGER, 2004).

O diâmetro caulinar cresceu linearmente aos níveis de 0,1057 e $0,0556 \mathrm{~mm}$ por aumento unitário de disponibilidade de nitrogênio no solo com os valores máximos estimados em 30,32 e 27,47 mm de diâmetro do caule das plantas com desfolha de 0 e $20 \%$, respectivamente. Já para as proporções de desfolha de 40 e $60 \%$, as plantas apresentaram aumento do diâmetro caulinar até os níveis estimados de 79,86 e 85,34 kg ha-1 de $\mathrm{N}$-fertilizante no solo, ajustando-se ao modelo polinomial quadrático (Figura 2).

De modo geral, o comportamento das plantas em relação ao diâmetro caulinar foi semelhante ao crescimento das plantas em altura, mostrando correlação positiva entre as duas variáveis de crescimento estudadas. Assim, os tratamentos que determinaram aumento na altura da planta, também influenciaram o aumento do diâmetro
Figura 2 - Curvas de resposta da mamoneira cv. BRS Energia sob diferentes doses de $\mathrm{N}$-fertilizante combinados com quatro porcentagens de desfolhamento sobre o diâmetro caulinar. Alagoinha-PB, 2009

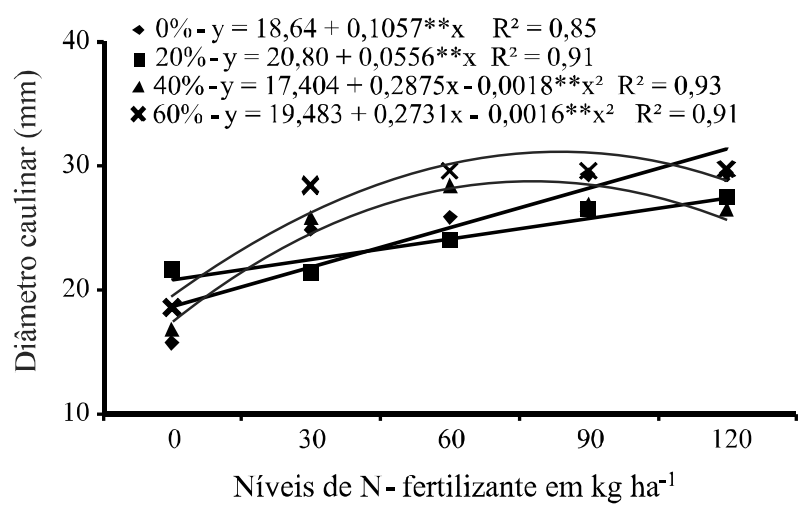

do caule, indicando elevada eficiência da espécie para transformar nutrientes absorvidos em fitomassa, mesmo quando suas folhas estão sendo suprimidas. $\mathrm{O}$ diâmetro caulinar é uma importante variável para o estudo de espécies vegetais utilizando tanto níveis de água quanto de nutrientes, pois segundo Araújo et al. (2000) expressa mais adequadamente as condições do sistema radicular das plantas avaliadas e este torna-se mais importante que o crescimento em altura.

O número de nós decresceu linearmente conforme aumentou-se o fornecimento do nitrogênio no tratamento controle ( $0 \%$ de desfolha). Esse resultado é consistente levando-se em consideração que ao aumentar o suprimento de nitrogênio no solo cultivado com a mamoneira, as plantas dessa espécie tende a aumentar o comprimento dos seus internódios em detrimento do número de nós (SEVERINO et al., 2006). Nos tratamentos com 20 e $40 \%$ de desfolha, os números de nós aumentaram até 15,21 e 15,41, respectivamente, com os valores máximos estimados em 31,75 e 23,38 $\mathrm{kg} \mathrm{ha}^{-1}$ de nitrogênio aplicados no solo (Figura 3).

Para a porcentagem de desfolha de $60 \%$ houve decréscimo no número de nós no nível estimado em $55,63 \mathrm{~kg} \mathrm{ha}^{-1}$ de nitrogênio aplicado ao solo, com o menor número de nós em 13,11, aumentando a partir desse ponto com o incremento do fertilizante. É provável, que o aumento do nitrogênio no solo tenha proporcionado uma recuperação do número de nós do caule principal das plantas, mesmo tendo suprimida $60 \%$ de sua folhagem. Vale destacar que o aumento do número de nós até o primeiro cacho, não significa crescimento da planta em altura, pois outros fatores estão relacionados com essa variável, como comprimento de internódios (KOUTROUBAS et al., 1999; SEVERINO et al., 2006). 
Figura 3 - Curvas de resposta da mamoneira cv. BRS Energia sob diferentes doses de $\mathrm{N}$-fertilizante combinados com quatro porcentagens de desfolhamento sobre o número de nós até o primeiro cacho. Alagoinha-PB, 2009

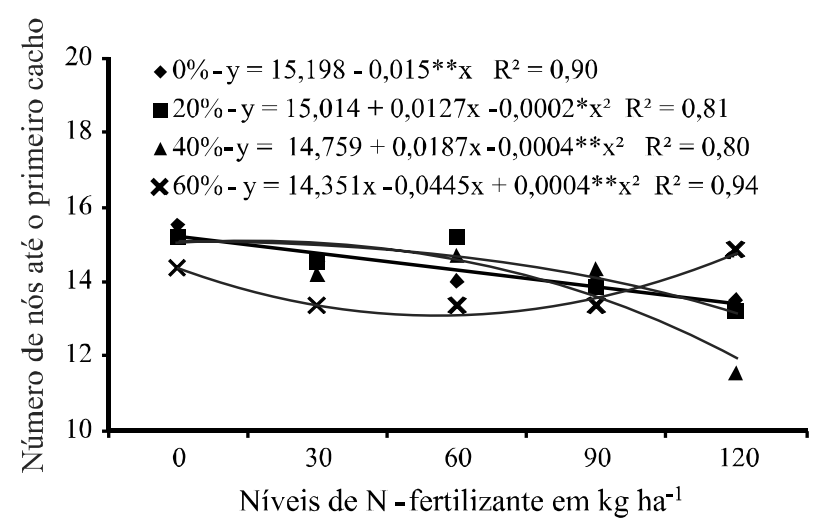

A massa de 100 grãos aumentou com o incremento do fertilizante nas proporções de desfolha de $0 ; 20 \%$ e $40 \%$ ajustando-se ao modelo quadrático, sendo que essa massa atingiu os valores de 30,83; 33,29 e 34,29 g com os níveis de nitrogênio no solo estimados em 72,50; 66,08 e $67,72 \mathrm{~kg} \mathrm{ha}^{-1}$, respectivamente. Para a maior proporção de desfolha $(60 \%)$ a massa de 100 grãos cresceu linearmente ao nível de $0,0718 \mathrm{~g}$ por aumento unitário do $\mathrm{N}$-fertilizante com valor máximo atingido em $35,39 \mathrm{~g}$ com a aplicação de $120 \mathrm{~kg} \mathrm{ha}^{-1}$ de nitrogênio (Figura 4).

Figura 4 - Curvas de resposta da mamoneira cv. BRS Energia sob diferentes doses de $\mathrm{N}$-fertilizante combinados com quatro porcentagens de desfolhamento sobre a massa de 100 grãos. Alagoinha-PB, 2009

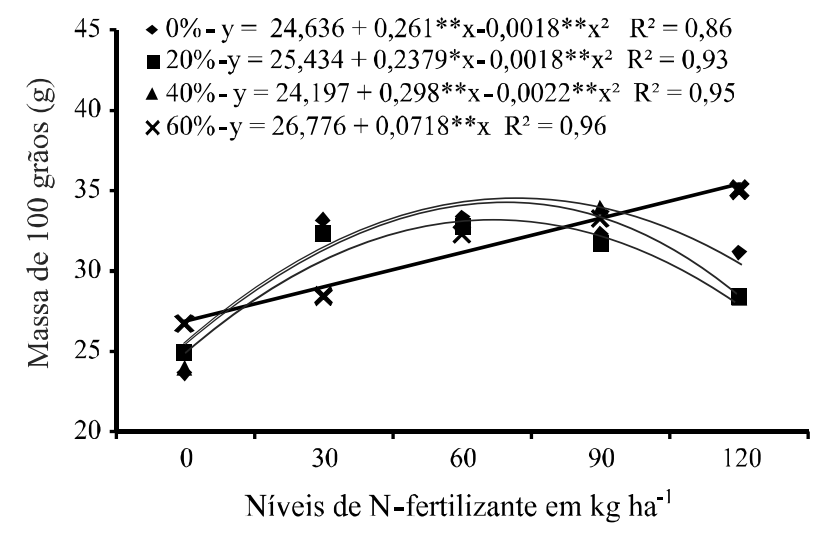

Tais resultados podem estar relacionados com a presença crescente nos níveis de nitrogênio, nutriente que promove crescimento vegetativo em detrimento da produção de grãos, com sua aplicação em excesso (SEVERINO et al., 2006). Porém, no tratamento com a maior proporção de desfolha (60\%) o aumento na massa de grãos foi crescente, o que pode ter ocorrido devido a planta está com pequena área foliar e direcionar suas reservas aos órgãos reprodutivos e não aos vegetativos como seria esperado. O fato é que, para o nitrogênio (N), a resposta da mamoneira à adubação é variável, ocorrendo, por vezes, efeito positivo, principalmente quando em presença de outros nutrientes (DONEDA et al., 2007; SEVERINO et al., 2006; SILVA et al., 2007), e, em outras, a resposta ao nitrogênio não há manifestação (SEVERINO et al., 2005). Vale acrescentar que a adubação nitrogenada em excesso, assim como o cultivo em solos de fertilidade elevada, pode ser prejudicial à mamoneira, particularmente para as cultivares de porte médio e crescimento indeterminado, por provocar o crescimento vegetativo excessivo em detrimento da produção (AZEVEDO et al., 1997; SCIVITTARO et al., 2008).

A produtividade em grãos seguiu a mesma tendência da massa de 100 grãos com as proporções de desfolha utilizada, adequando-se ao modelo quadrático em 0 e $40 \%$ de desfolha com a produtividade atingindo os valores máximos em 828,66 e $1.032,50 \mathrm{~kg} \mathrm{ha}^{-1} \mathrm{de}$ grãos com os níveis de $\mathrm{N}$-fertilizante estimados em 81,27 e 99,96 kg ha-1, respectivamente. Para $20 \%$ e para a maior proporção de desfolha $(60 \%)$ a análise de regressão evidenciou efeito linear ao nível de 3,065 e $3,551 \mathrm{~kg}$ por incremento unitário do $\mathrm{N}$-fertilizante atingindo valores máximos estimados em 910,02 e $888,058 \mathrm{~kg} \mathrm{ha}^{-1}$ de grãos, respectivamente (Figura 5).

Figura 5 - Curvas de resposta da mamoneira cv. BRS Energia sob diferentes doses de $\mathrm{N}$-fertilizante combinados com quatro porcentagens de desfolhamento sobre a produtividade de grãos. Alagoinha-PB, 2009

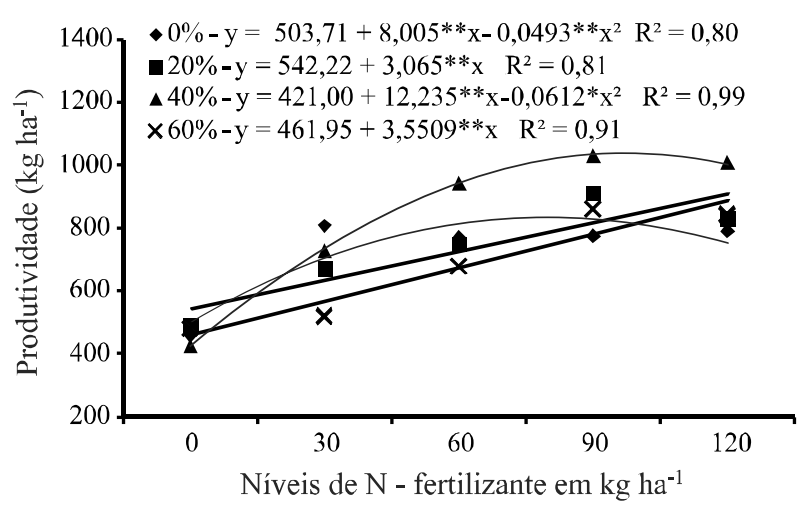


Os tratamentos que influenciaram os resultados para a massa de 100 grãos, também proporcionaram a obtenção de resultados semelhantes para produtividade de grãos. Tal comportamento produtivo dessa variedade de mamona (BRS-Energia) pode ter apresentado correlação positiva entre essas variáveis, de modo que as combinações das proporções de desfolha com os níveis de nitrogênio, mostraram eficiência até certa dosagem de $\mathrm{N}$-fertilizante com as proporções de desfolhamento artificial, diminuindo a partir desse ponto, exceto para o desfolhamento de $60 \%$, que apresentou crescimento linear.

É possível que os fatores $\mathrm{N}$-fertilizante e desfolhamento artificial tenham atuado conjuntamente e proporcionado aumentos na massa de grãos e, por conseguinte aumentos na produtividade desses grãos. Entretanto, Koutroubas et al. (2000) observaram que o aumento na produtividade da mamoneira está associado ao maior número de racemos e de frutos por planta, mas não com a massa de grãos. Com isso comprova-se o que Severino et al. (2006); Doneda et al. (2007) e Silva et al. (2007) relataram sobre a adubação nitrogenada na mamoneira afirmando que com a aplicação do nitrogênio $(\mathrm{N})$, a resposta da mamoneira é variável, ocorrendo, por vezes, efeito positivo, principalmente quando em presença de outros nutrientes e, em outras, não são observadas manifestações das plantas de mamona (SEVERINO et al., 2005).

\section{CONCLUSÕES}

1. As variáveis de crescimento aumentam com os níveis de $\mathrm{N}$-fertilizante nas proporções de desfolhamento artificial de até $20 \%$. A partir dessa proporção, há tendência para obtenção de maior crescimento vegetativo aplicando doses menores de nitrogênio;

2. A massa de 100 grãos e a produtividade de grãos aumentam com doses menores que $120 \mathrm{~kg} \mathrm{ha}^{-1}$ de $\mathrm{N}$ fertilizante em proporções de desfolhamento artificial de até $40 \%$, mostrando que há correlação positiva entre essas variáveis de produção da mamoneira;

3. A desfolha artificial quando combinada com adubação nitrogenada provoca alterações nos componentes de crescimento e de produção da mamoneira, sendo importante avaliar até que ponto é economicamente viável a aplicação do $\mathrm{N}$-fertilizante e a possibilidade do uso de fontes alternativas desse nutriente

\section{AGRADECIMENTOS}

À FAPESQ/CNPq pela concessão de bolsa DCR ao primeiro autor e apoio financeiro ao projeto e ao DSER/CCA/UFPB e EMEPA-PB pelo apoio logístico.

\section{REFERÊNCIAS}

ALMEIDA, A. P. et al. Desenvolvimento e produção da variedade de mamona BRS-188 sob diferentes níveis e fontes de macronutrientes. Revista Pesquisa, v. 1, n. 1, p. 27-35, 2007.

ARAÚJO, D. da C. et al. Efeito do volume de água e da cobertura morta sobre o crescimento inicial do maracujazeiro amarelo. Revista Brasileira de Engenharia Agrícola e Ambiental, v. 4, n. 1, p. 121-124, 2000.

AZEVEDO, D. M. P. de. et al. Recomendações técnicas para o cultivo da mamona (Ricinus communis L.) no Brasil. Campina Grande: EMBRAPA - CNPA, 1997. 52 p. (Circular Técnica, 25).

BARROS JUNIOR, G. et al. Consumo de água e eficiência do uso para duas cultivares de mamona submetidas a estresse hídrico. Revista brasileira de engenharia agrícola e ambiental, v. 12, n. 4, p. 350-355, 2008.

BELTRÃO, N. E. M. et al. Ecofisiologia. In: AZEVEDO, D. M. P.; BELTRÃO, N. E. M. O Agronegócio da Mamona no Brasil. 2. Ed. Brasília Embrapa, 2007.

BRASIL, Ministério da Agricultura. Levantamento Exploratório - Reconhecimento de Solos do Estado da Paraíba. Rio de Janeiro; Equipe de Pedologia e Fertilidade do Solo (MA), 1972, 670p.

CARVAlHO, E. V. de et al. Densidade de plantio em duas cultivares de mamona no sul de Tocantins. Revista Ciência Agronômica, v. 41, n. 3, p. 387-392, 2010.

COSCIONE, A. R.; BERTON, R. S. Barium extraction potential by mustard, sunflower and castor bean. Scientia Agricola, v. 66, n. 1, p. 59-63, 2009.

DINIZ NETO, M. A. et al. Adubação NPK e épocas de plantio para a mamoneira. II - componentes das fases vegetativas e reprodutivas. Revista Ciência Agronômica, v. 40, n. 3, p. 417-426, 2009.

DONEDA, A. et al. Resposta da cultura da mamona (Ricinus communis L.) a doses de N, Pe K em sistema plantio direto no Sul do Brasil. In: CONGRESSO BRASILEIRO DE CIÊNCIA DO SOLO, 31., 2007, Gramado. Anais... Porto Alegre: Sociedade Brasileira de Ciência do Solo, 2007. 1 CD-ROM.

EMPRESA BRASILEIRA DE PESQUISA AGROPECUÁRIA BRASILEIRA ALGODÃO. Adubação da mamoneira. Campina Grande: Embrapa Algodão, 2007a. 1 folder.

EMPRESABRASILEIRADEPESQUISAAGROPECUÁRIA ALGODÃO. BRS - Energia. Campina Grande: Embrapa Algodão, 2007b. 1 folder.

EMPRESA BRASILEIRA DE PESQUISA AGROPECU[ARIA ALGODÃO. Centro Nacional de Pesquisa de Solos (Rio de Janeiro). Sistema brasileiro de classificação de solos. Brasília: Sistema de Produção de Informação - SPI, 1999. 412 p.

EVANGELISTA, A. R. et al. Avaliação da composição química de folhas de mamona (Ricinus communis L.) 2006. Disponível 
em: www.biodiesel.gov.br/docs/congressso2006/ agricultura/Av aliacaoComposi\%E7\%E3o10.pdf. Acesso em 23 jul. 2010.

FERREIRA, G. B. et al. Variação do crescimento vegetativo e produtivo de alguns genótipos de mamona em diferentes populações de cultivo. In: CONGRESSO BRASILEIRO DE MAMONA, 2., 2006, Aracajú. Anais... Campina Grande: Embrapa Algodão, 2006.1 CD-ROM.

FERREIRA, P. V. Estatística aplicada a agronomia. 3. ed. Maceió: EDUFAL, 2000. 422 p.

GONÇALVES, N. P. et al. Cultura da Mamoneira. Informe Agropecuário, v. 26, p. 28-32. 2005.

GUIMARÃES, M. M. B. et al. Fontes de fertilizantes nitrogenados e seus efeitos no crescimento da mamoneira. Engenharia Ambiental: Pesquisa e Tecnologia, v. 5, n. 3, p. 203-219, 2008.

KOUTROUBAS, S. D.; PAPAKOSTA, D. K.; DOITSINIS, A. Adaptation and yielding ability of castor plant (Ricinus communis L.) genotypes in a Mediterranean climate. European journal of agronomy, v. 11, n. 3/4 227-237, 1999. Disponível em: <http:// www.elsevier.com/locate/eja>. Acesso em: 12 jul. 2006.

KOUTROUBAS, S. D.; PAPAKOSTA, D. K.; DOITSINIS, A. Water requirements for castor oil crop (Ricinus communis L.) in a Mediterranean climate. J. Agro. \& Crop Science, v. 184, n. 1, p. 33-41, 2000. Disponível em: <http://www.sciencedirect. com/science>. Acesso em: 11 jul. 2006.

NAKAGAWA, J.; NEPTUNE, A. M. L. Marcha de absorção de nitrogênio, fósforo, potássio, cálcio e magnésio na cultura da mamoneira (Ricinus communis L.) cultivar Campinas. Anais da Escola Superior de Agricultura Luiz de Queiroz, v. 28, p. 323-337, 1971

PACHECO, D. D. et al. Produção e disponibilidade de nutrientes para mamoneira (Ricinus communis) adubada com NPK. Revista de Biologia e Ciências da Terra, v. 8, n.1, p. 153-160, 2008.

QUEIROGA, V. de P.; SANTOS, R. F. dos. Diagnóstico da produção de mamona (Ricinus communis L.) em uma amostra de produtores do Nordeste brasileiro. Revista Brasileira de Oleaginosas e Fibrosas. v. 12, n. 1, p. 9-23, 2008.
RIBEIRO, S. et al. Resposta da mamoneira cultivar BRS-188 Paraguaçu à aplicação de nitrogênio, fósforo e potássio. Revista Ciência Agronômica, v. 40, n. 4, p. 465-473, 2009.

SCHMALZ, C. A. et al. Produção e Decomposição de Folhas de Mamona Durante o Ciclo da Cultura. 2007. Disponível em: http://w3.ufsm.br/ppgcs/congressos/CBCS_ Gramado/ Arquivos\%20trabalhos/Produ\%E7\%E3o\%20e\%20Decomposi \%E7\%E3o_Cassiano\%20R..pdf. Acesso em 29 jul. 2010.

SCIVITTARO, W. B. et al. Adubação nitrogenada para cultivares de mamona no Rio Grande do Sul. EMBRAPACLIMA TEMPERADO, 2008. 38 p. (Boletim de Pesquisa e Desenvolvimento, 77).

SEVERINO, L. S. et al. Crescimento e produtividade da mamoneira adubada com macronutrientes e micronutrientes. Pesquisa Agropecuária Brasileira, v. 41, n. 4, p. 563-568, 2006.

SEVERINO, L. S. et al. Crescimento e produtividade da mamoneira sob fertilização química em região semiárida. Campina Grande: Embrapa Algodão, 2005. 19 p. (Embrapa Algodão. Boletim de pesquisa e desenvolvimento, 62).

SILVA, F. de A. S.; AZEVEDO, C. A. V. de. Versão do programa computacional assistat para o sistema operacional windows. Revista Brasileira de Produtos Agroindustriais, v. 4, n. 1, p. 71-78, 2002.

SILVA, T. R. B. da et al. Adubação nitrogenada em cobertura na cultura da mamona em plantio direto. Pesquisa Agropecuária Brasileira, v. 42, n. 9. p. 1357-1359, 2007.

SOUZA, A. dos S. et al. Épocas de plantio e manejo da irrigação para a mamoneira. I - crescimento e produtividade. Revista Ciência Agronômica, v. 38, n. 4, p. 422-429, 2007.

TAIZ, L.; ZIGER, E. Fisiologia Vegetal. 3. ed. Porto Alegre: Artmed, 2004. 719 p.

ZUCHI, J. et al. Componentes do rendimento de mamona segundo a ordem floral e época de semeadura no Rio Grande do Sul. Revista Ciência Agronômica, v. 41, n. 3, p. 380-386, 2010 . 